\title{
Topic: Under-5 children mortality in Chad from 1990 to 2017: Analysis of the Global Burden of Disease data
}

NODJIMADJI TAMLENGAR MARTIAL ( $\square$ tammartial@whu.edu.cn )

Wuhan University

YU Chuanhua

Wuhan University Zhongnan Hospital

Research article

Keywords: Neonatal mortality; Under-5 mortality; Infant mortality; Mortality analysis; Chad

Posted Date: June 14th, 2019

DOI: https://doi.org/10.21203/rs.2.10328/v1

License: @ (1) This work is licensed under a Creative Commons Attribution 4.0 International License. Read Full License 


\section{Abstract}

Background: Ending preventable death for newborns and children is one of the new goals set by the United Nations as the Sustainable Development Goals (SDGs). This goal should be reached by the year of 2030, in all United Nations countries including the Republic of Chad. Chad is one of the Sub-Saharan countries in central Africa, where infants' mortality is still high, due to many conditions. The objective of this study is to analyze the mortality in under-5 children in Chad from 1990-2018, with data from the Global Burden of Disease (GBD). Methods: Data from GBD (GHDx input source) of under-5 mortality in Chad 1990-2018 was analyzed using IBM SPSS Statistics version 25 by performing a Two-way ANOVA to check for the interaction effect between gender, age, and mortality. A Mean compare was used to determine the most involved gender and the most involved age in under-5 mortality in Chad. Results: The male gender $12510(95 \% \mathrm{Cl}-4867-2988852 \%)$ is higher than the female gender $11401(95 \% \mathrm{Cl}-5976-2877948 \%)$ in under-5 mortality in Chad from 1990-2018. This can also be interpreted by the percentages of YLLs in both genders with the male's $1085166(95 \% \mathrm{Cl} 1067788$ $110254452 \%$ ) which is also higher than the female's 988032 (95\% Cl 970654-1005410 48\%). In the different age groups used in this study, the overall Data showed that the 1-4years age group is the most affected with a highest number (Deaths and YLLs) 717547 (45.6\%), followed by the Post neonatal group 552360 (35.1\%), and finally the Early neonatal group 302924 (19.3\%). Conclusion: Under-5 mortality in Chad is still higher compared to the new Sustainable Development Goals set by the United Nations.

\section{Background}

In order to promote infant survival and to plan for better policies and strategies, understanding the cause of infant mortality, and studying and suggesting new policies are necessary.

During the last 30 years, significant progress had been made in reducing child mortality in the world. This progress had been observed in many countries and regions resulting in a substantial improvement of child survival [1-3]. The reduction of child mortality by two thirds (2/3) is the objective of Millennium Development Goal 4 (MDG 4) [4]. Meanwhile, The New Sustainable Development Goals (SDGs) have as objective to end preventable newborns and children deaths by 2030 [5].

The Republic of Chad (Chad) is a landlocked country in Central Africa (African continent), which covers an area of 1,284,000 km2, with a population estimated at 15.6 in 2019 by the latest world population estimates [6].

In 2018, a statistical update on countries made by the United Nations Development Programme (UNPD) puts Chad in the position of 186 out 189 countries and territories according to its Human Development Indices (HDI), which was evaluated at 0.404 [7]. Such low HDI value reflects the country's difficulties in many fields such as education, health system, and life quality, due to the low economic situation as its direct consequences.

One of the objectives of the Global Burden of Disease (GBD) is to furnish a global assessment of child mortality and morbidity, by recording child health achievements relatively to the millennium development goal era by sex (male and female), and age (early-neonatal, late-neonatal, post-neonatal, and 1 to 4years). It also furnishes estimates of child mortality categorized by age, sex, and causes over the time, through studies and surveys by recording and providing metrics such as Years of Life Lost (YLL), Years Lived with Disability (YLD), Disability-Adjusted Life Years (DALY), Incidence rate (I), Prevalence rate, Total Fertility rate (TFR), and mortality rate of the overall burden of a disease and for all causes. Its estimates are used by many scientists in many studies [8].

The Republic of Chad has signed many of the United Nations treaties, and adheres therefore to many of its organizations such as UNPD and UNICEF, in order to promote and provide a better life quality to the Chadian population through projects, programs, and campaigns within all ages.

Chad, as a member of those countries which signed the United Nations treaties to improve child survivor, is still fighting its way to reach line of those countries which have reached the SDGs.

In this study, we will first describe the infant mortality evolution in Chad from 1990 to 2017 according to the gender criteria (male and female), and age (Early neonatal, Post neonatal, and 1 to 4years), then secondly determine the gender and the age subset with a higher mortality statistic, using data from the Global Burden of Disease.

\section{Methods}

\section{1-Study Design:}


This study analyzes data from the Global Burden of Disease (GBD) 2017 realized on Chad about under-5 mortality from 1990 to 2018.

For this study, we estimate Variables numbers by Age group (early-neonatal, post-neonatal, and 1 to 4 years) for Total causes, and the Gender criteria had also been taken into consideration. Early Neonatal is defined as the 28 days after birth. Post Neonatal is the 29 th day to the 364th day after birth. 1 to 4years starts from 365th day to 4years.

A General Linear Model Univariate analysis was conducted to identify the interaction effect of gender and age on under-5 mortality.

A Mean compare was performed to identify the most involved gender and the most affected age group in under-5 mortality.

\section{2-Data Source:}

GBD database is controlled by the Institute for Health Metrics and Evaluation (IHME), which is in Washington, USA [9].

The sources of data used in the construction of the GBD database involve representative national surveys, vital records systems, cancer registries, and health care use data [10].

Details about GBD data are located in the GBD Data Input Sources Tool in the GHDx section [10].

\section{3-Variables:}

Related variables to this study are the followings:

- Death or Mortality: Mortality represents the proportion of people who died from a disease. Its calculation is according to the following formula:

See Figure 3 for Equation 1

- YLL, which defines the number of years a person could have lived if the illness that killed him/her had not occurred, is calculated by multiplying the number of deaths times the standard life expectancy at the age of death (Number of deaths $x$ standard life expectancy at the age of death). The calculation formula is as follow:

\section{$Y L L=N \times S L E$}

$\mathrm{N}$ represents the Number of Death due to condition, SLE represents the Standard Life Expectancy at the age of death which can differ from age to another.

\section{4-Data Analysis:}

The statistical software used to analyze data is IBM SPSS Statistics version 23.

\section{Results}

Gender and age can both be affected by mortality, but that effect can differ within the gender as well as the age group.

A descriptive analysis (Table 1) and a General Linear Model Univariate (Two-way ANOVA) showing the interaction effect between the variables and the Gender (Variables*Gender), the Variables and the Age (Variables*Age), and the Variables, the Gender, and the Age (Variables*Gender*Age) was conducted (Table 2).

A Mean compare was used to compare the means of each Variable according to each gender and age group to specify the most vulnerable gender (Table 3 ) and age group affected by mortality (Table 4).

\section{A-Mortality:}


In Chad, from 1990 to 2017, the total number of Deaths in infants (under-5) is 11955. The male gender is highly exposed with 12510 (95\% Cl -4867-29888 52\%) than the female gender with 11401 (95\% Cl -5976-28779 48\%).

In the male gender, the mortality is as followed in the age subset: Early neonatal 8007 (95\%Cl -22092-38106 21\%), Post neonatal 12817 (95\% Cl -17282-42917 34\%), and 1-4years 16707 (95\% Cl-13393-46805 45\%).

The female gender mortality in different age subsets are as followed: Early neonatal 5626 ( $95 \% \mathrm{Cl}-24473-3572516 \%)$, Post neonatal $12170(95 \% \mathrm{Cl}-17928-4227036 \%)$, and 1-4years 16407 (95\% Cl-13692-46506 48\%) as described in Table 1.

\section{B-YLLs:}

As shown in Table 1, the total number of YLLs in infant mortality in Chad during the period of 1990-2018 is 1036599 . In the male gender, the total number is 1085166 ( $\mathrm{Cl} 1067788-110254452 \%)$, and 988032 (Cl 970654-1005410 48\%) in the female gender. The male gender is higher than the female gender, with the same percentage as in mortality.

The male gender YLL number in Early neonatal age subset is 703651 (95\% Cl 673551-733750 22\%). In the Post neonatal age subset, we have 1120495 (95\% Cl 1090395-1150595 34\%), and the 1-4years age subset has 1431352 (95\% Cl 1401253-1461452 44\%).

As it can be seen in Table 2, the interaction effect within and between all categories are statistically significant. According to our research questions, we will be interested in the interaction effect between the variables and the gender, the interaction effect between the variables and the age, and finally the interaction effect between the variables, the gender, and the age.

- The interaction effect between the Variables and the Gender (Variables*Gender) is statistically significant. It demonstrates the effects of gender and the variable. This interaction is represented by this following statistical identity:

$F=29.543 P=.000(P)^{2}=.084$ Observed Power $=1.000$.

- The interaction effect between Variables and Age (Variables*Age) shows a strong relationship which is statistically significant. This proves the high influence of the Ages on the Variables. The following is its statistical criteria, according to Table 2:

$F=710.025 P=.000(P)^{2}=.814$ Observed Power $=1.000$

- Table 2 also shows the interaction effect between the Variables, Gender, and Age (Variable*Gender*Age). This relationship is also statistically significant which does not verify the null hypothesis. It also interprets the relationship effect between the above three. It is represented by this following statistical criteria as its statistical identity:

$F=10.088 P=.000(P)^{2}=.059$ Observed Power $=.985$.

All the interactions are statistically significant. This rejects the null hypothesis and proves that there is a difference between all groups.

In order to determine which gender has higher mortality, and which age group is more involved in infant's mortality, we compared the Means in the male and female gender

(Table 3), followed by a comparison of Means in the age category (Table 4). The ANOVA statistical report for the Means Compare is mentioned below each table.

As recorded in Table 3, the male gender has a total mean of 548838 (52\%), which is slightly higher than the female gender $499717(47 \%)$. When comparing the Standard Deviation of the male and the female gender, we can also notice that the male gender has a Standard Deviation of 583489.867, therefore, not far from the Standard Deviation in the female gender which is

563294.955. These two values are very closed and justify the $P$ value .433 which is higher than the (.05), because their observed difference (Standard Deviation) between the two categories are not statistically significant.

This means that the male and the female gender are different groups and have a different interaction effect on infant's mortality in Chad, but with a difference which is not statistically significant. 
When looking at Table 4, then we can observe that every age subset mean is different from one to each other. First comes the 1-4years which is 717547 (45.6\%), followed secondly by the in the Post neonatal subset 552360 (35.1\%), and finally the Early neonatal subset $302924(19.3 \%)$.

The Standard Deviation in each age subset are considerably different and gradually grows according to the age subset ascension as follow: Early neonatal 314926.988, Post neonatal 547743.706, and 1-4years 710144.333.

View all these statistical indexes, including the $P$ value $(P=.000)$ of the mean compare in the age category, we can say that age has a significant interaction effect with infant's mortality, and the 1-4years age subset is the most affected in Chad from 1990-2017.

\section{Discussion}

In general, under-5 mortality was decreased in the world. Estimated at 93 deaths per 1000 live births, it has dropped to 39 deaths per 1000 live births from 1990-2017 [11].

In Sub-Saharan countries, under-5 mortality is still higher reaching 76 deaths per 1000 live births in 2017 [12]. The Republic of Chad, as a Sub-Saharan country, with a low HDI [7], is also exposed to this scourge.

When analyzing the mortality in under-5 infants in Chad from 1990 to 2017, with data from GBD, we can observe that:

Under-5 mortality is almost equal in the male and the female gender, with a higher Years of Life Lost in the male gender than the female gender (Figure 1);

Under-5 mortality is lower in Early neonatal age subset and gradually grows higher in the Post neonatal age subset, then in the 1-4years which becomes the most affected age subset. This observation can also be seen in the Years of Life Lost line (Figure 2).

From 1990 to 2018 in Chad, under-5 mortality has considerably decreased in the male and the female, but the male gender percentage for under- 5 mortality is still higher than the female gender. This increases the number in Years of Life Lost (YLLs) in the male gender compared to the female gender, as demonstrated in this study.

In the different age subsets (Early neonatal, Post neonatal, and 1-4yeras), the numbers of mortality are also different from one age subset to another, in both genders. The number in Early neonatal is lower than the number in Post neonatal, which is smaller compared to the 14years subset. This also means that in the 1-4years age subset, the number of Years Life Lost (YLLs) is very high compared to the Post neonatal age group. Meanwhile, the number of Years Life Lost in Early neonatal age group is smaller compared to the Post neonatal age.

We can also notice that the more the age grows, the more chances of mortality the infants are exposed to, which is also explained by the wide difference in the numbers of Years Life Lost in different age groups, and the mortality rate for under-5 is 119.55 deaths per 1000 live births.

In 2015, a report from the World Health Organization (WHO) had evaluated Chad as one of the countries in world which did not succeed in reaching the goals fixed by the WHO Target 4.A about the reduction of the under-5 mortality rate by $2 / 3$ by the year 2015 for the WHO countries, due to absence or limited progress [13].

Another study had shown that, although the under- 5 mortality rate is still at a high range ( 119.55 deaths per 1000 live births), under-5 mortality in Chad has been downgrading [14]. The under-5 mortality rate in this study had been decreasing over the years from 210.80 deaths in 1990 to 185.10 deaths in 2000, then 127.30 deaths per 1000 births in 2016.

Another study from the United Nations Inter-agency Group for Child Mortality Estimation (IGME) showed that the mortality in the under-5 age group in Chad has decreased [15]. In this study, the under-5 mortality rate was estimated at 212.8 deaths per 1000 live births in 1990 in Chad. In 2000, for the same country, IGME estimated the mortality rate for under-5 infants at 186.5 deaths per 1000 live births. In 2017 , the under- 5 mortality rate was estimated at 123.2 deaths per 1000 live births by the IGME.

All these studies showed that the government of Chad and its development partners still have a lot to do, as many other Sub-Saharan countries, to reach the goals underlined by the SDGs, which is the reduction of the under- 5 mortality rate to at least 25 deaths per 1000 live births by the year 2030 . The delay is this race has many causes which influence directly or indirectly under-5 mortality is Chad. 
Some studies demonstrated that in order to reduce under-5 mortality, a country should have a better income per habitat [16,17], and also a higher education especially in the female gender in reproduction age [18], a low fertility rate, a strong health program, a good supervision and management of certain public resources.

A report from the United Nations Educational Scientific and Cultural Organization (UNESCO) estimated the literacy rate, among the 15 years and over of the Chadian population at $22.31 \%$ of a general population estimated around $15,000,000$ people in 2016 [19]. The literacy rate, defined as the ability to read and write, was estimated at $13.96 \%$ in the female population, which is very lower compared to the rate in the male population estimated at $31.33 \%$ by the same report. This shows the unequal repartition of the education percentage between males and females, which can influence indirectly under-5 mortality in Chad.

The 2018 statistical report of UNPD ranked Chad 186th among the countries with a low Human Development Indices (HDI) out of 189 countries [9].

Beside the mentioned issues related to economic and educational development, malnutrition is also a major problem in Chad, as described in an online report of Action Against Hunger [20]. Due to many internal and external causes in the country, many people have moved in or within country for safer and better life condition. The influx of refugees in the country or around the cities created an important need for humanitarian assistance around the camps and cities. This situation leads to many difficulties such as decreased water supply, contaminated water and environment, food insecurity, and diseases caused by lack of sanitation.

Added to that, Chad, as a Sub-Saharan country, also suffers from climate-change leading to decreased in the rain and floods. This provokes insufficient food production due to lack of agricultural development related to poverty, and children are the most exposed [21].

All these factors don't favor the country's fight against under- 5 mortality. But they should stop the fight, in order to reach the SDGs 2030 fixed by the UN, as some Sub-Saharan countries with low HDI as Chad already did, such as Rwanda and Eritrea.

\section{Conclusion}

The Republic of Chad has managed to decrease under-5 mortality over the years. The country, with the help some United Nation Organizations, had reduced the number of under- 5 mortality. However, many conditions are to be improved for Chad to significantly decrease under-5 mortality.

Our study has demonstrated that the mortality in under-5 infants has decreased by yet higher with 119.55 deaths per 1000 live births. The male gender is more affected by this mortality than the female gender. As the children grow, they gradually become more exposed to mortality, as observed in different age groups.

Despite the decrease in under-5 mortality, Chad still has many efforts to make in many different domains such as education, economic, and Heath to reach the new Sustainable Development Goals by 2030.

For recommendations to decrease infants' mortality rate as the recommended rate by the SDGs, we suggest that the government of Chad and its United Nations partners should:

Improve governmental policies,

Reinforce of political strategies,

Prioritize of education especially in the female gender and rural areas,

Improve of transportation system to allow the population to easily reach health center, and local sell product markets,

Increase opportunities for general physicians to have complementary or higher programs specifically about maternal, neonates, and infants' health by also giving scholarships for further studies,

Usage of modern agricultural techniques in order to increase food production, and

provide food safety.

\section{List Of Abbreviations}

Page 6/14 
SDGs: Sustainable Development Goals

GBD: Global Burden of Disease

YLL: Years of Life Lost

YLD: Years of Life Disability

DALY: Disability-Adjusted Life Years

MDG: Millennium Development Goal

UNPD: United Nations Development Programme

HDI: Human Development Index

TFR: Total Fertility Rate

UNICEF: United Nations Children's Fund

IHME: Institute of Health Metrics and Evaluation

USA: United States of America

WHO: World Health Organization

UNESCO: United Nations Educational Scientific and Cultural Organization

IGME: United Nations Inter-agency Group for Child Mortality Estimation.

\section{Declarations}

\section{Ethics approval and Consent to participate:}

Not applicable.

\section{Consent for Publication:}

Not applicable.

\section{Availability of Data and Materials:}

The datasets analyzed in this study are located in the Global Burden of Disease (GBD) data under GHDx section. Data source link is as follow:

Global Burden of Disease Collaborative Network.

Global Burden of Disease Study 2017 (GBD 2017) Results. Seattle, United States: Institute for Health Metrics and Evaluation (IHME), 2018 [10].

Available from http://ghdx.healthdata.org/gbd-results-tool.

\section{Competing interests:}

The authors declare that they have no competing interests.

\section{Funding:}


This research was funded by: The National Natural Science Foundation of China (Grant No:81773552), the National Key Research and Development Program of China (No:2018YFC1315302, 2017YFC1200502).

\section{Authors' Contributions:}

NTM downloaded, analyzed, and interpreted the data and the results under the supervision of YC as educative mentor (supervisor).

All authors read and approved the final manuscript.

\section{Acknowledgements:}

Not applicable.

\section{References}

[1] Rajaratnam JK, Marcus JR, Flaxman AD et al (2010) Neonatal, postneonatal, childhood, and under-5 mortality for 187 countries, $1970-$ 2010: a systematic analysis of progress towards Millennium Development Goal 4. Lancet 375:1988-2008. doi: 10.1016/SO140-

6736(10)60703-9

[2] Lozano R, Wang H, Foreman KJ et al (2011) Progress towards Millennium development goals 4 and 5 on maternal and child mortality: an updated systematic analysis. Lancet 378:1139-1165. doi: 10.1016/S0140-6736(11)61337-8

[3] Liu L, Oza S, Hogan D et al (2015) Global, regional, and national causes of child mortality in 2000-2013, with projections to inform post-2015 priorities: an updated systematic analysis. Lancet 385:430-440. doi: 10.1016/S0140-6736(14)61698-6

[4] MDG monitor: Reduce Child mortality, Millennium Development Goals (2016)

\section{https://www.mdgmonitor.org/mdg-4-reduce-child-mortality/}

Accessed $27^{\text {th }}$ May 2019

[5] United Nations: Sustainable Development Goals (2015)

\section{https://sustainabledevelopment.un.org/}

Accessed $27^{\text {th }}$ May 2019

[6] World Population Estimates (2019): Chad Population Estimates (2019)

\section{https://www.worldometers.info/world-population/chad-population/}

Accessed $30^{\text {th }}$ May 2019

[7] UNPD Human Development Report: Statistical updates Chad (2018)

\section{http://www.hdr.undp.org/en/countries/profiles/TCD}

Accessed 30 $30^{\text {th }}$ May 2019

[8] GBD 2015 Eastern Mediterranean Region Neonatal, Infant, and under-5 Mortality Collaborators Int J Public Health (2018) 63(Suppl 1): 63. https://doi.org/10.1007/s00038-017-0998-x

[9] Global Burden of Diseases: Institute of Heath Metrics and Evaluation (IHME): 


\section{https://www.healthhdata.org/}

Accessed $27^{\text {th }}$ May 2019

[10] Global Burden of Disease Collaborative Network.

Global Burden of Disease Study 2017 (GBD 2017) Results. Seattle, United States: Institute for Health Metrics and Evaluation (IHME), 2018. Available from http://ghdx.healthdata.org/gbd-results-tool.

[11] Global Health Observatory (GHO) data: Undre-5 mortality situation in the world (2017)

\section{https://www.who.int/gho/child_health/mortality/mortality_under_five_text/en/} Accessed $27^{\text {th }}$ May 2019

[12] UNICEF: Under-five mortality: Sub-Saharan countries (2018)

\section{https://data.unicef.org/topic/child-survival/under-five-mortality/}

Accessed $27^{\text {th }}$ May 2019

[13] Organisation Mondiale de la Santé: Statistiques sanitaires mondiales 2015

\section{https://www.who.int/gho/publications/world_health_statistics/fr/}

Accessed $27^{\text {th }}$ May 2019

[14] Index Mundi: Chad- Mortality rate, under-5 (per 1,000 live births) 2016

\section{https://www.indexmundi.com/facts/chad/indicator/SH.DYN.MORT}

Accessed $27^{\text {th }}$ May 2019

[15] UN Inter-agency Group of Child Estimation (IGME): Under-5 mortality rate total: Chad (2018)

\section{https://childmortality.org/data}

Accessed $27^{\text {th }}$ May 2019

[16] Jahan S (2008) Poverty and infant mortality in the Eastern Mediterranean region: a meta-analysis. J Epidemiol Community Health 62:745-751. doi: $10.1136 /$ jech.2007.068031

[17] O'Hare B, Makuta I, Chiwaula L, Bar-Zeev N (2013) Income and child mortality in developing countries: a systematic review and metaanalysis. J R Soc Med 106:408-414. doi: 10.1177/0141076813489680

[18] Gakidou E, Cowling K, Lozano R, Murray CJL (2010) Increased educational attainment and its effect on child mortality in 175 countries between 1970 and 2009: a systematic analysis. Lancet Lond Engl 376:959-974. doi: 10.1016/S0140-6736(10)61257-3

[19] UNESCO Institut de Statistique de l'UNESCO: Tchad éducation et alphabétisme 2016

\section{http://uis.unesco.org/fr/country/td}


[20] Action Against Hunger/ ACF International report: Chad: country profile 2010

http://www.actionagainsthunger.org/sites/default/files/publications/student-center-country-profile-chad.pdf

\section{Accessed $27^{\text {th }}$ May 2019}

[21] Bain, L. E., Awah, P. K., Geraldine, N., Kindong, N. P., Sigal, Y., Bernard, N., \& Tanjeko, A. T. (2013). Malnutrition in Sub-Saharan Africa: burden, causes and prospects. The Pan African medical journal, 15, 120. doi:10.11604/pamj.2013.15.120.2535

\section{Tables}


95\% Confidence Interval

\begin{tabular}{llllllll} 
Variables & Gender & Age & N & Mean & Std. Error & Lower bound & Upper Bound \\
\cline { 7 - 8 } Deaths & male & Early neonates & 28 & 8007.219 & 15299.850 & -22092.371 & 38106.809 \\
\cline { 3 - 8 } & & Post neonates & 28 & 12817.543 & 15299.850 & -17282.047 & 42917.133 \\
\hline & & 28 & 16706.127 & 15299.850 & -13393.463 & 46805.717 \\
\hline & Total & 84 & 12510.296 & 8833.372 & -4867.710 & 29888.303
\end{tabular}

\begin{tabular}{clccccc} 
female & Early neonates & 28 & 5626.201 & 15299.850 & -24473.389 & 35725.791 \\
\cline { 2 - 7 } & Post neonates & 28 & 12170.893 & 15299.850 & -17928.698 & 42270.483 \\
\hline 1-4 years & 28 & 16407.166 & 15299.850 & -13692.424 & 46506.756 \\
\hline Total & 84 & 11401.420 & 8833.372 & -5976.587 & 28779.426
\end{tabular}

\begin{tabular}{lllllll} 
YLLs male & Early neonates & 28 & 703651.088 & 15299.850 & 673551.498 & 733750.679 \\
\cline { 2 - 7 } & Post neonates & 28 & 1120495.506 & 15299.850 & 1090395.916 & 1150595.097 \\
\hline $1-4$ years & 28 & 1431352.942 & 15299.850 & 1401253.352 & 1461452.532 \\
\hline Total & 84 & 1085166.512 & 8833.372 & 1067788.506 & 1102544.519
\end{tabular}

\begin{tabular}{clccccc} 
female & Early neonates & 28 & 494414.137 & 15299.850 & 464314.547 & 524513.727 \\
\cline { 2 - 7 } & Post neonates & 28 & 1063958.817 & 15299.850 & 1033859.226 & 1094058.407 \\
\hline 1-4 years & 28 & 1405724.808 & 15299.850 & 1375625.218 & 1435824.398 \\
\hline Total & 84 & 988032.587 & 8833.372 & 970654.581 & 1005410.594
\end{tabular}

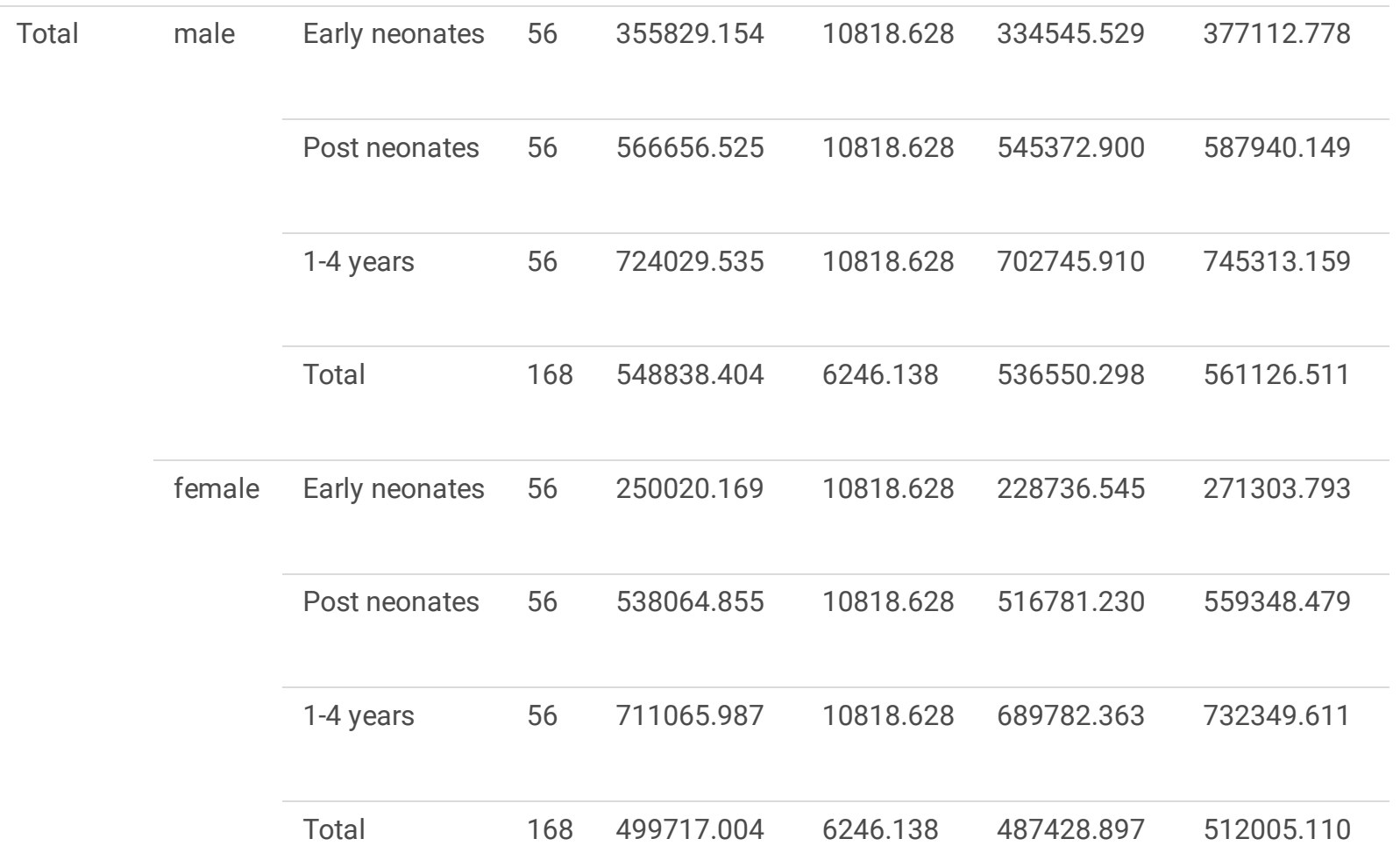


YLLs: Years of Life Lost

1-4years: 1 to 4years old

N: Number of Samples

Std. Error: Standard Error

Table 1: Descriptive Statistics:

\begin{tabular}{|c|c|c|c|c|c|c|c|}
\hline Source & Type III Sum of Squares & df & Mean Square & $\mathrm{F}$ & Sig. & $\begin{array}{l}\text { Partial Eta } \\
\text { Squared }\end{array}$ & $\begin{array}{l}\text { Observed } \\
\text { Power }^{\text {b }}\end{array}$ \\
\hline Corrected Model & $107925254286551.660^{a}$ & 11 & 9811386753322.877 & 1496.918 & .000 & .981 & 1.000 \\
\hline Intercept & 92355349234365.780 & 1 & 92355349234365.780 & 14090.606 & .000 & .978 & 1.000 \\
\hline Variables & 88191154378433.550 & 1 & 88191154378433.550 & 13455.277 & .000 & .976 & 1.000 \\
\hline Gender & 202684609045.846 & 1 & 202684609045.846 & 30.923 & .000 & .087 & 1.000 \\
\hline Age & 9759583507218.725 & 2 & 4879791753609.362 & 744.507 & .000 & .821 & 1.000 \\
\hline Variables * Gender & 193637009587.964 & 1 & 193637009587.964 & 29.543 & .000 & .084 & 1.000 \\
\hline Variables * Age & 9307563720490.008 & 2 & 4653781860245.004 & 710.025 & .000 & .814 & 1.000 \\
\hline Gender * Age & 138385587038.884 & 2 & 69192793519.442 & 10.557 & .000 & .061 & .989 \\
\hline $\begin{array}{l}\text { Variables * Gender * } \\
\text { Age }\end{array}$ & 132245474736.909 & 2 & 66122737368.454 & 10.088 & .000 & .059 & .985 \\
\hline Error & 2123622822300.914 & 324 & 6554391426.855 & & & & \\
\hline Total & 202404226343218.280 & 336 & & & & & \\
\hline Corrected Total & 110048877108852.580 & 335 & & & & & \\
\hline
\end{tabular}

1. R Squared $=.981$ (Adjusted R Squared $=.980$ )

2. Computed using alpha $=.05$

Table 2: Test between Subjects effects: Interaction between Variables and Gender; Variables and Age; and Variables, Gender, and Age. 


\begin{tabular}{llllllll} 
Gender & Mean & N & Std. Deviation & Minimum & Maximum & \% of Total N & \% of Total Sum \\
\hline Male & 548838.40 & 168 & 583489.867 & 5888 & 1577163 & $50.0 \%$ & $52.3 \%$ \\
\hline Female & 499717.00 & 168 & 563294.955 & 4066 & 1569757 & $50.0 \%$ & $47.7 \%$ \\
\hline Total & 524277.70 & 336 & 573152.781 & 4066 & 1577163 & $100.0 \%$ & $100.0 \%$
\end{tabular}

$a=.05$

$F=.616 \quad P=.433(P>a)$

Table 3: Mean Compare table between the male and the female gender according to the Variables Values.

\begin{tabular}{llllllll} 
Age & Mean & N & Std. Deviation & Minimum & Maximum & \% of Total N & \% of Total Sum \\
\hline Early & 302924.66 & 112 & 314926.988 & 4066 & 831894 & $33.3 \%$ & $19.3 \%$ \\
Neonatal & & & & & & & \\
\hline Post Neonatal & 552360.69 & 112 & 547743.706 & 9553 & 1233516 & $33.3 \%$ & $35.1 \%$ \\
\hline $1-4$ & 717547.76 & 112 & 710144.333 & 13374 & 1577163 & $33.3 \%$ & $45.6 \%$ \\
\hline Total & 524277.70 & 336 & 573152.781 & 4066 & 1577163 & $100.0 \%$ & $100.0 \%$
\end{tabular}

$\mathrm{a}=.05$

$F=16.203 \quad P=.000(P<a)$

Table 4: Mean Compare table of the Age group according to Variables Values.

\section{Figures}

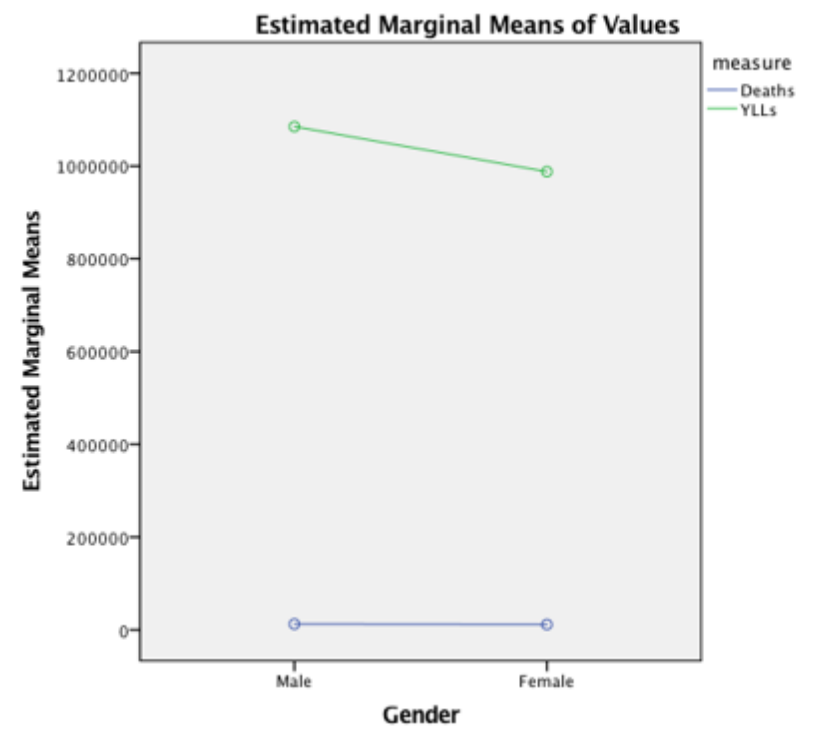

Figure 1 
Mortality and YLLs in the male and the female gender. From this plot, we can observe that the mortality between the male and the female gender is quite similar. Yet, the Years of Life Lost (YLLs) in the female gender is lower (smaller) than the male gender, which is higher.

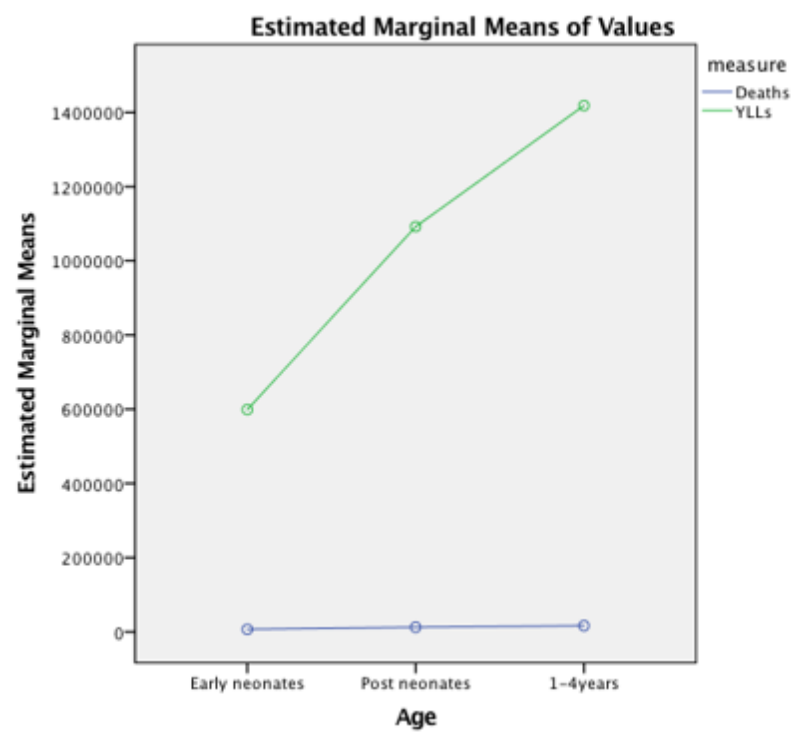

\section{Figure 2}

Mortality and YLLs in Early neonatal, Post neonatal, and 1-4years. This plot shows that the mortality in Early neonatal is lower than the mortality is Post neonatal age subset, which gradually grows higher at age of 1-4years. This remark works also for the years of life lost in the age group.

\section{Death $\left(\right.$ Mortality) $=\frac{\text { Number of deaths }}{\text { Total population }}$}

\section{Figure 3}

Death or Mortality: Mortality represents the proportion of people who died from a disease. Its calculation is according to the following formula

\section{Supplementary Files}

This is a list of supplementary files associated with this preprint. Click to download.

- Data.csv 